\title{
El caso Neruda: el origen de un detective creado por un poeta. Aproximaciones a la literatura de Roberto Ampuero
}

\author{
El caso Neruda: the origin of a detective created by a poet. \\ Approaches to Roberto Ampuero's literature
}

\author{
Diana Ramírez \\ Universidad de Texas A\&M, Estados Unidos
}

\begin{abstract}
Resumen: La novela El caso Neruda tiene como centro la historia de los orígenes de Cayetano Brulé, el detective que protagoniza las novelas del género negro creadas por Roberto Ampuero, escritor chileno cuya obra resulta fundamental en este subgénero dentro de la literatura latinoamericana contemporánea. El presente artículo se enfoca al análisis de la relación metaliteraria entre el personaje de Brulé, su vínculo ficcional con el poeta Pablo Neruda y el juego que crea Ampuero entorno a la biografía del poeta, convirtiéndolo en un personaje literario no sólo por su creación poética, sino por haber llevado una vida que, en la multiplicidad de sus historias, facilita la especulación literaria.
\end{abstract}

Palabras clave: Neruda, Cayetano Brulé, género negro, Roberto Ampuero, literatura chilena.

Abstract: The novel The Neruda Case is the story of the origins of Cayetano Brulé, the detective who appears in all black novels created by Roberto Ampuero, the Chilean writer whose work is essential in this sub-genre within contemporary Latin American literature. This article focuses on the analysis of the metaliterary relationship between the character of Brule, his fictional link with the poet Pablo Neruda and the context that Ampuero creates around the biography of the poet. In this novel Neruda is a literary character not only for his poetic creation, but for having led a life in the multiplicity of their stories, facilitating literary speculation..

Keywords: Neruda, Cayetano Brulé, black novel, Roberto Ampuero, Chilean literatura.

La literatura latinoamericana, si bien ha sido creada con una amplia gama de influencias, siempre muestra un producto único, nutrido de su historia y contextos sociales. La novela policiaca ofrecida por Roberto Ampuero no es una excepción. Este escritor, de origen chileno (nacido en Valparaíso el 20 de febrero de 1953), cuya vida cosmopolita se trasluce en su obra literaria, ha trabajado la novela de detectives con una perspectiva que critica los sistemas sociales que rigen América Latina y su relación con el mundo global a partir de su historia; lo cual lo inserta en una tradición en la que destacan Paco Ignacio Taibo II (México), Manuel Vásquez Montalbán (España), entre otros escritores.

Este escritor es el autor del detective Cayetano Brulé, el protagonista de sus novelas policiacas ¿Quién mató a Cristián Kustermann? (1993), Boleros en La 
Habana (199), El alemán de Atacama (1996), Cita en el Azul Profundo (2001), Halcones de la noche (2005), El caso Neruda (2008) y Bahía de los misterios (2013). En esta penúltima obra es donde se explica el origen del detective. En este texto Ampuero convierte en personaje a Pablo Neruda y lo lleva a crear la carrera de Brulé. El caso Neruda es una novela donde ambos personajes poseen voz y el mismo protagonismo. La organización del texto se basa en los nombres de cada una de las mujeres que marcaron la vida del poeta y que servirán de pistas al investigador. En este artículo se plantea la importancia de esas figuras, la formación y características que distinguen a Brulé y el juego que plantea la novela dentro del sistema literario del que forma parte.

El presente investigador es un individuo totalmente latinoamericano que poco tiene que ver con el distinguido héroe-detective de la novela negra clásical. Cayetano Brulé (cuyo nombre recuerda el segundo apellido de su padre: Roberto Ampuero Brulé) es un hombre de unos 50 años (dentro de la saga que protagoniza), nacido en La Habana, quien ha crecido en Florida, nada atlético, con lentes que acusan su miopía, un cabello no muy abundante ya y un bigote tupido que le da un aire mexicano. Sobre su personaje, en entrevista Ampuero declara:

Cayetano, un cubano que vive en el puerto de Valparaíso, de donde sale a investigar por el mundo, surge de una realidad sorprendente que descubrí hace mucho, cuando comencé a vivir en Cuba: que Chile y Cuba expresan dos polos diferentes del alma latinoamericana. Son dos formas diferentes, a ratos opuestas, de vivir la vida y de disfrutarla, marcadas por causas históricas, raciales y culturales distintas. Pero pese a que constituyen dos extremos opuestos, forman parte del alma única de Latinoamérica. Me interesaba, por lo tanto, la mirada de un latinoamericano que fuese capaz de entender tanto las claves del Cono Sur como del Caribe, de un ser que pudiese moverse tanto en el húmedo calor del Caribe como en los fríos inviernos de la Patagonia, de un ser que pudiese entender el mundo influido por África y el mundo influido por las culturas indígenas del continente. El Caribe y el Cono Sur son opuestos, pero son complementarios en tanto sensibilidad latinoamericana. $Y$ no olvidemos que Cayetano Brulé es la mirada del continente sobre los

\footnotetext{
1 Guillermo García-Corales, quien se ocupa de estudiar los cambios en la temática dentro de la novela policial chilena, sostiene al respecto: "La desentralización del sujeto, la fragmentación de las ideologías, el descalabro de las utopías tradicionales, la desligitimación de la autoridad y la combinación híbrida de elementos heterogéneos, representan algunas de las configuraciones asociadas a la posmodernidad, las cuales conforman una parte significativa del sustrato ideológico y estético de las novelas publicadas en la década de los noventa por los escritores de la generación del 80, es decir, aquellos nacidos cerca o después de 1950. En todo caso, varios autores de este periodo ficcionalizan esas configuraciones de manera problemática, aludiéndolas con distancia crítica. Por una parte, establecen ciertos límites con respecto a esa fase posmoderna que se solaza con la determinación ética y la plurisignificación del lenguaje. Por otra, trazan estrategias que incluyen, por ejemplo, la focalización compensatoria de segmentos del pasado que resultan acogedores al contraponerse constantemente al horizonte inhóspito y desencantado del presente. Este ímpetu de carácter nostálgico y melancólico adquiere una dinámica relevante en la narrativa detectivesca de la serie negra desarrollada en Chile, que a partir de los noventa transita a la democracia después de 16 años de dictadura militar" (1999: 81). Esta perspectiva permite vincular El caso Neruda con el planteamiento de García-Corales puesto que se trata de un texto que desentraña el origen del personaje y sus primeros roces con un sistema histórico con el cual ha de lidiar a lo largo de la serie que protagoniza. Además de que el planteamiento del crítico vincula a Roberto Ampuero con una tradición literaria con sus temas y sus características.
} 
mundos del Norte industrial. Sentí que Cayetano Brulé tenía que ser universal dentro de nuestra América (2008).

Este personaje aparece como un sujeto ajado por sus circunstancias, un individuo sin planes que se ha dejado llevar por la vida, puesto que no posee una filosofía profunda o analítica de la existencia. Es un hombre de placeres elementales y sencillos como una buena copa, un apetecible plato de comida (sin ser un gourmet, como el detective de Vásquez Montalbán) y es también un amante cuyos vínculos no son pasionales, sino que su relación implica dos seres solitarios juntos precisamente para compartir el momento que se tiene. Sus lazos con la vida, con el mundo, se caracterizan por la simpleza: Suzuki, un ayudante; Esperanza, una perrita rescatada de las calles que vive con él y un divorcio del cual sólo queda el recuerdo como la experiencia que lo ha llevado a Valparaíso y a su vida actual. Brulé no es un personaje de grandes ideologías, éstas lo han atrapado en algún punto de su existencia. El crimen y la historia para Cayetano Brulé son parte de su cotidianidad.

El desarrollo de Brulé como personaje es crucial en la narrativa de Ampuero; ya que es el detective que protagoniza la mayor parte de su producción literaria. La propuesta de lectura que se elabora en este artículo es mostrar el carácter netamente literario con el que Ampuero construye este personaje, ya que El caso Neruda es la novela que demarca el origen de Brulé y destaca la mayor parte de los rasgos con los cuales el detective es descrito en otros textos del autor. En esta novela Ampuero se dedica a ofrecerle al lector la historia de la profesión y formación de Brulé. Dentro de este texto el escritor muestra al personaje como una creación surgida de la literatura, destinada a moverse en el sistema literario, siempre concebido como una realidad que se toca con la historia, como se verá a continuación.

\section{El caso Neruda: el origen poético de Brulé}

Esta novela posee un estilo que resulta intenso en su mezcla de las características de los ambientes cosmopolitas de Brulé (sus viajes a Cuba, Alemania y, en el presente caso, a Bolivia)22, sus alusiones históricas al golpe de Estado en Chile (1973) durante el gobierno de Salvador Allende y por su referencia a la figura de Pablo Neruda. Es importante aclarar que, si bien esta novela retoma partes de la vida del poeta chileno, no se trata de una biografía, así que en este trabajo se respetará ese contrato ficcional demarcado por el texto. La presencia de Neruda como personaje y dentro del contexto histórico chileno, permite observar -a una muy prudente distancia- la transición hacia la dictadura militar y dota al texto de un matiz social y literario no perceptible de forma tan acentuada en los libros anteriores protagonizados por Brulé.

\footnotetext{
2 En las novelas de Ampuero usualmente el autor retoma esta serie de visitas, que es identificada por Clemens A. Franken como parte de un rasgo biográfico que el autor imprime a su obra: "La obra literaria de Roberto Ampuero, uno de los representantes más relevantes de la novela negra chilena de la última década, está marcada, en forma decisiva, por sus 20 años de vida en el extranjero, ante todo, en Cuba y Alemania. Este largo tiempo de exilio voluntario le otorga a sus novelas policiales un marcado carácter internacional e intercultural, que se manifiesta no sólo la concepción de su protagonista, el detective cubano-chileno Cayetano Brulé, sino también en la trama, que suele desarrollarse tanto en escenarios chilenos como en extranjeros" (2002: 89).
} 
La convergencia de elementos biográficos e históricos en la novela no es casual. Al parecer, Ampuero está empleando la novela policiaca como un medio (como una más de las vertientes de la literatura) para llevar hasta el lector un estilo que abre y expone un contexto social que, dentro de la tradición policiaca-distinguida por su apertura hacia el público-, favorece la asimilación y la comprensión hacia un determinado contexto socio-histórico. Por esta razón, dentro del texto pervive una denuncia social, un posicionamiento que no gira en torno del personaje central, sino que, al igual que el lector, él se ve inmerso en los avatares políticos que le superan a medida que avanza el relato. De allí su habilidad para sobrevivir: Brulé es el personaje humanizado en el conjunto de sus circunstancias; la sencillez de su filosofía resulta perfecta para invitar al lector a ahondar en la complejidad de lo histórico y a reflexionar sobre la biografía de un poeta que cumplió una función social, literaria y política en el Chile que relata la novela.

En el presente caso, el crimen no es un asesinato, un robo, una desaparición. Es un crimen de orden poético concerniente al pasado del personaje de Neruda: el primer encargo que formará la carrera de Brulé es resolver la cuestión a cerca de su romance con una bella mujer, saber si ese amorío lo convirtió en padre y hallar a la posible hija. Los elementos básicos (los viajes intercontinentales, su incursión en diferentes intrigas políticas y sus aventuras circunstanciales) son el toque que concede el autor al estilo de esta tradición para acompañar a su detective.

Cayetano Brulé, como la mayoría de los héroes modernos ${ }^{3}$, se encuentra en la encrucijada de lo cotidiano: un matrimonio decadente y la búsqueda de hallar una profesión que le permita subsistir, es decir, a la caza de un sentido existencial inmediato, no rodeado de grandes preguntas, sino pragmático. Pero ¿̇cómo descubrir un lugar para quedarse cuando se es un permanente extranjero? El camino que se abre para él es el de la búsqueda, guiado y bajo la tutelar confianza del Poeta. Este primer contacto que inevitablemente hace pensar en La Divina Comedia (al recurrir al poeta como maestro y como aquel que ha de guiar al héroe en su travesía), si bien abre un diálogo intertextual con la literatura como sistema, también sigue su propio camino al mostrar la imperfección y la dualidad de los dos personajes a lo largo del texto.

Tanto Brulé como Neruda cambian gradualmente a lo largo del texto. Ampuero muestra el lado juvenil, ingenuo y anhelante de mundo de su investigador y el lado sabio, cosmopolita e intelectual del poeta, pero también, en su evolución, los personajes van creciendo: uno para convertirse en un detective ávido de curiosidad y un tanto desencantado de sus descubrimientos, otro para dejar de lado al hombre culto obsesionado con las descripciones fogosas y apasionadas de mujeres juveniles, para aparecer como un personaje humanizado con sus oportunismos y elecciones; un Neruda que no sólo buscaba usar a las mujeres para

\footnotetext{
3 Sobre la evolución del héroe en la literatura, Hans George Gadamer sostiene: "Sólo en la época moderna ha sido sustituida [la épica] por el arte de la novela, que ya no recurre al mundo primitivo mítico o a la tradición religiosa. Desde Cervantes hasta Joyce o hasta el enigmático Kafka ya no se narran las hazañas de los héroes. En vez de la canción del héroe, se canta la canción de las lamentaciones de la humanidad y la aventura de la vida; la historia de la formación del hombre y el padecimiento de la sociedad con su leyenda. Los cambios imprevisibles del acontecer y las sorpresas que brotan del corazón humano son los mundos que desde entonces dan vida a un género literario inagotable" (1997: 107). Este aspecto es importante ya que la novela policiaca retrata a personajes que buscan tener matices cercanos al hombre del día a día, perseverando por conservar su empleo y sostenerse en su realidad, tal como Cayetano Brulé.
} 
su experiencia poética, sino un hombre que vivió y se nutrió de ellas como parte de su ascenso en su carrera literaria.

Esta es una parte crucial de los descubrimientos de Brulé, quien los asimila y observa sin juzgarlos, pero poco a poco (al igual que parece ser la intención de la novela con el lector) baja del pedestal de ídolo al poeta, situándolo en un plano humano, ya no sólo considerado como el Nobel de las palabras, sino como un ser lleno de contradicciones, ansioso por resolver su pasado y angustiado por la muerte.

El encuentro entre ellos tiene lugar en un ambiente que el lector llega a conocer mediante las memorias del detective, en una situación casual. Es uno de esos choques que hacen parecer que todo ha hallado un sentido finalmente, puesto que Brulé se halla en busca de trabajo y su título de detective (obtenido por correspondencia) comienza a usarlo no sólo para rendirle frutos económicos, sino la gran aventura de su existencia. Este joven investigador es recordado por el narrador del modo siguiente: "Cayetano decidió radicarse en Valparaíso al llegar a Chile. En 1971, del brazo de su mujer de entonces, María Paz Ángela Undurranga Cox. Eran los días de Salvador Allende y la Unidad Popular, de una efervescencia social desenfrenada que no desembocaría en lo que el pueblo había soñado sino en la dictadura del general Augusto Pinochet" (Ampuero, 2008: 19) ${ }^{4}$.

En este contexto sucede el encuentro entre Neruda, una figura amada, respetada por el pueblo chileno, y un joven detective, que está un poco perdido y sin pistas sobre su vida. El poeta, en ese encuentro inicial, es el símbolo de la fe en la ideología, de la creación y de ese hombre que se ha abierto paso en la vida llevando a la literatura como bandera. Y sin embargo Ampuero, en esta novela, desmitifica la figura del poeta y lo convierte en un hombre imperfecto, usando la literatura para mostrar una cara distinta del amado poeta chileno.

Por su parte, Brulé mantiene su carácter de personaje literario. Si bien, luego de haber leído las recomendaciones hechas por el personaje de Neruda (George Simenon, sobre todo), el detective se identifica con Andrea, el discípulo de Galileo (otro guiño literario empleado por Ampuero), el texto deja ver al lector y al propio Cayetano cómo es el hecho de saberse creado: "Era como si la obra, mediante ese personaje, se esforzase por colocarle un espejo ante los ojos. No podía negarlo. Con la misma pasión que se había entregado aquel huérfano italiano a la ciencia por emular a su maestro, él, Cayetano, como detective creado por Neruda, se entregaba a la causa de éste y eso, debía admitirlo, lo llenaba de orgullo y lo revestía de una vitalidad insospechada." (201)

Asumir que es una creación forma parte del carácter humilde de Cayetano para aceptar las cosas como le han sido dadas. Esta situación no significa que el personaje carezca de identidad, sino por el contrario, tal docilidad habla de una generosa capacidad de adaptación para ir asumiendo los procesos y, en su momento, el camino que plantea cada caso en el que se ve involucrado. La genuina admiración de Brulé por Neruda no es parte de su conocimiento literario, sino que el detective observa al poeta como el hombre esforzado, el latinoamericano que recorrió el mundo con talento y arrojo para situarse en el lugar que ahora ocupa. No es que el habanero sea un ingenuo o idolatre al poeta desde la ignorancia, más bien es la nobleza de entregarse a una mano maestra para que

\footnotetext{
4 AMPUERO, R. (2008): El caso Neruda. Bogotá: Editorial Norma. A partir de esta cita, todas las referencias a la novela se realizarán sólo con el número de página.
} 
vaya conformándole poco a poco el camino, como todo aprendiz confiado en la sabiduría de su guía.

Las características de Brulé asoman en El caso Neruda como un perfil que conduce al lector a ver cada pormenor entretejido y revelado. Una de las escenas que muestra este tipo de situaciones es el detalle de la inseparable y peculiar corbata lila de guanacos, primer regalo del poeta al detective y que le acompaña en todas las descripciones a lo largo de las cinco novelas que protagoniza: "Te la doy para que te proteja. Tal vez no te sirva para ganarte un Nobel, pero al menos para que no hablen mal de ti como detective" (62).

En cada uno de estos momentos, en este tipo de detalles, el narrador imprime realismo y vida, y crea un pasado en el personaje. Estos datos van complementando, llenando huecos y creando guiños que envuelven al lector dentro de ese mundo. Asimismo, es interesante observar que a la par que Brulé se humaniza y se vuelve más familiar, más íntimo, esta novela, que elabora un acercamiento a la figura de Neruda, lo muestra también desprovisto de la majestad del homenaje. La narración lo acerca mucho más a un ser humano que a un poeta glorificado y es esta característica uno de los sellos que distinguen esta novela dentro del neopolicial latinoamericano 5 .

El caso Neruda es una de las novedades en la narrativa de Ampuero dentro de la tradición policial hispanoamericana, ya que en ella se emplean diversos recursos tales como utilizar esta literatura para relacionarla con la biografía de un escritor, desmitificar una figura canónica y hacerlo desde un estilo que no pretende ser reductivo ni mucho menos humillante, sino que permite que sea la literatura la que se encargue de mostrar a Neruda más humano, más en un encuentro justo entre las características de un ser de carne y hueso que de un ídolo laureado.

La novela policiaca tiene como objetivo tradicional aclarar algún misterio a los ojos del lector y ello ha de acrecentar la carrera del detective protagonista. En este caso, Ampuero conduce a reflexionar sobre los personajes que crean la literatura y el misterio no es tanto la idea de un crimen sino un hondo pasado que resulta tormentoso en su confusión, en la ansiedad que genera y el impacto posible dentro del personaje de Neruda, a través del cual el narrador plantea interesantes cuestionamientos hacia el propio acto de la creación. Una de sus grandes preguntas es si la existencia se trasciende mediante la literatura o en la preservación de la estirpe. Estas dudas que acosan al poeta en su etapa terminal deben ser

\footnotetext{
${ }^{5}$ Este término se atribuye al escritor mexicano Paco Ignacio Taibo II. Luego de él, algunos críticos lo han empleado para distinguir este tipo de novelas dentro de la tradición detectivesca, tal como plantea José Pomis: "El neopolicial latinoamericano no puede ser identificado llanamente con el relato policial tradicional, característico de la cultura europea y anglosajona, ni con el llamado hard-boiled estadounidense. La narrativa policial tradicional [...] utiliza el motivo del crimen para desarrollar una narrativa crucigramática cuyo propósito inmediato es la desorientación del lector. [...] El neopolicial latinoamericano es, como su nombre pareciera indicarlo, una tercera alternativa genética que aprovecha los recursos narrativos de las dos modalidades mencionadas, una de formación euro y anglocentrista y la otra, manifestación típica de la cultura angloamericana de los años de mil novecientos treinta. [...] El neopolicial latinoamericano sería un discurso narrativo característico de la cultura hispanoamericana, comparable, en este sentido, a otros tipos de discursos identificados como propios de la misma cultura, como, por ejemplo, el discurso de "lo real maravilloso" de Alejo Carpentier, o el discurso hiperbólico de Gabriel García Márquez" (2005: 153-154). Sin embargo, para acotar este término de un modo sintético y a propósito de la obra de Roberto Ampuero, Vania Barraza Toledo propone: "En suma el relato neo-policial como expresión de una nueva novela policiaca es un nuevo modo para presentar una realidad basada en el juego de la ilusión" (2003: 171).
} 
aclaradas por el detective, quien no es un avezado en literatura, pero que, a su modo, responde al caso con su investigación.

Asimismo, otro de los puntos clave de la novela es que permite ver de manera muy clara no sólo el origen, sino una especie de esquema en el destino del personaje de Cayetano Brulé: el asunto que casualmente cae en sus manos para ser investigado (llamada venturosa que, por supuesto, es parte de toda novela policiaca); un mundo de viajes iniciado con una pesquisa un tanto escuálida que se va nutriendo a lo largo de la aventura; tropezar con cierta intriga de carácter político; el hallazgo del propósito para el cual se le ha contratado y, desde luego, el vínculo de la odisea del detective con un momento concreto en la historia contemporánea de América Latina.

Estas etapas van mostrando poco a poco la complejidad de las novelas de Roberto Ampuero habitadas por Brulé. No se trata sólo de un carismático detective inmerso en la pasión de la búsqueda, sino también de ir desarrollando en estos textos una idea del vínculo entre crimen e historia, contexto y circunstancias individuales, personajes históricos y personajes que permiten especular sobre el perfil de las situaciones, de los momentos, y que van sensibilizando al lector con estos factores como parte de la comprensión no sólo de la noción de crimen, sino de la historia. Ampuero elabora relatos que vinculan la ficción con lo histórico como un modo de ir posibilitando los lazos entre la curiosidad del lector y el interés por la biografía o la historia de momentos y personajes que resultan claves en Latinoamérica.

Así como los detectives Pepe Carvahlo de Vásquez Montalbán o Héctor Belascoarán Shayne de Taibo poseen características que los van personificando dentro de sus relatos y los hacen habitar no una novela, sino una serie de ellas, el giro que Ampuero concede a la figura de su investigador estriba en su relación con la ficción y su capacidad para habitarla. Como ya se ha mencionado, Brulé no tiene nada que ver con el detective clásico y, dentro de la tradición contemporánea, este personaje se va nutriendo de contextos históricos y realidades literarias. Dentro de las primeras novelas que protagoniza, este personaje jamás se destaca por una capacidad deductiva, una impresionante o exquisita cultura, gran fuerza física o destreza basada en la experiencia. Como latinoamericano que ha experimentado la historia de un continente es, ante todo, un sobreviviente. Las características de Brulé son parte importante en la evolución del personaje del detective, tal como refiere José Colmeiro a propósito de los protagonistas de la novela policiaca:

La figura del investigador, justiciero o vengador, de acuerdo con los cánones formulados por Hammett y Chandler, casi siempre un perdedor o un marginado, de ambigua moralidad, y cuestionable conducta, pero poseedor de un código de honor superior al de sus principios; idealista en su intento de llegar hasta el final en el descubrimiento de la verdad aun a riesgo de exponer su vida, cínico en su reconocimiento de la esterilidad de su empeño, convencido de la imposibilidad radical de cambiar el estado de las cosas; su investigación resulta un progresivo proceso de descubrimiento del grado de podredumbre de la sociedad a su alrededor, tanto mayor escarba y araña su superficie (1994: 214).

Esta serie de características atañen al personaje de Cayetano Brulé, por lo que es posible observar que, pese a las diferencias, Ampuero mantiene una línea concreta 
en su relación con la tradición detectivesca. Asimismo, otra parte fundamental de Cayetano Brulé es su ya nombrada capacidad de adaptación y su criterio para recibir las situaciones y la vida con mente abierta y una actitud que, lejos de cuestionar a sus interlocutores, sólo los acepta. En El caso Neruda es posible ver de cerca esta cualidad con las contradicciones planteadas por el personaje del poeta. Si bien en este escrito no es posible detenerse sobre la biografía del Nobel chileno, sólo habrá que reflexionar acerca de la construcción literaria que elabora Roberto Ampuero en torno a esta figura y su relación con el carácter de su detective.

Neruda aparece como una figura al mismo tiempo trágica y humana, marcada por el deseo, la pasión y las ambiciones de un curioso joven latinoamericano ansioso por la fama y el éxito. Ampuero presenta ante sus lectores un retrato que no corresponde en lo absoluto con el ideal de un poeta revolucionario. La humanización de este personaje es parte del juego ficcional de la novela: es, por así decirlo, parte del trabajo literario eliminar el proceso de ensalzar a un poeta y mostrarlo con un sesgo más humano, lejano del pedestal, acercarlo a las contradicciones. Tal vez por ello en los diálogos entre los dos personajes una de las situaciones que mejor va habitando Brulé es no entender nada de poesía y aceptar más a la humanidad circundante. Aceptar al hombre que le traza el camino del mismo modo que ha decidido consentir que la existencia es una serie de circunstancias entrelazadas.

Pablo Neruda asoma en la novela primero ante los ojos del joven y desempleado detective como una figura oscura, sombría, cubierta de fama y de gloria pero sin personalidad determinada:

La interrupción había logrado que Cayetano al fin girara. Así advirtió que el hombre no estaba a sus espaldas sino de pie casi a su lado. Y, asombrado, lo reconoció. Durante la fiesta no se había atrevido a acercársele, inhibido no sólo por el estrecho círculo de admiradores que lo rodeaban sino también por la autoridad que atribuía a esa figura gruesa de movimientos lentos, cuya lánguida mirada de grandes párpados de saurio había ido del mar a él y de vuelta al mar durante esa conversación en que él ni siquiera se había dignado a mirarlo. Y ahora el gran poeta y distinguido embajador de Salvador Allende en Francia, se alejaba tironeado por aquella mujer. La emoción le sacudió de pronto su cuerpo y le agolpó la sangre en la cabeza (30).

Este retrato del encuentro aparece vívido en la memoria del narrador. Y si bien Neruda asoma sólo como el laureado poeta, a lo largo del relato genera su carácter, sus propios y cruciales matices que le hacen habitar la novela. Personaje capaz de crear los versos más tristes o los más apasionados, también es capaz de ir marcándole el camino a una serie de féminas cuya huella es honda y, mayormente, amarga. ¿ Por qué Roberto Ampuero crea en esta novela -para el lector- una figura con tales características que, a la par que humaniza, también desmorona al ídolo de la literatura chilena? El escritor, al ser entrevistado, responde:

La novela construye un Neruda que es tan legítimo como el que construyen las biografías de él. No ha habido voces críticas. Neruda es una gran figura y convive perfectamente con las versiones sobre su vida. Pero yo creo que esta novela baja a Neruda del pedestal de santo en que muchos lo colocan y lo convierte en un ser de carne y hueso, de luces y 
sombras, de generosidades y mezquindades, en un gran artista mucho más complejo, real y entrañable que el Neruda de bronce que algunos intentan imponer. Creo que la gente está leyendo El caso Neruda con tanto interés porque presenta a un Neruda de carne y hueso, a un poeta que fue capaz de amar y odiar, de entregarse por entero a una causa y ser un calculador frío, un artista que supo manejarse entre la poesía y la política y a veces cometió los peores errores, como celebrar a Stalin y a Batista. Pero Neruda es un genio de la poesía, invadió el mundo con su arte y amó y traicionó, y amó y fue infiel, y todo eso lo recoge El caso Neruda desde la óptica de la ficción (2009).

Y quizás también, porque en el terreno de la literatura se concede el derecho de ficcionalizar personajes vivos y muertos, porque en el mundo de la creación con palabras, éstas pueden adquirir la carga que el narrador desee darles. Es decir, parte de la función de la literatura es jugar con las pesquisas y las posibilidades de toda existencia, desmoronarla y dotarla de posibilidades, sin que haya una magia exclusiva inclinada a la idealización.

\section{La organización de El caso Neruda: los personajes femeninos y su relación con Neruda}

Si bien, como ya se ha mencionado antes, el presente texto no se ocupará de la biografía del poeta chileno, es importante observar que la novela se construye con base en cada uno de los personajes femeninos que tuvo relación con él. Las mujeres de su vida son quienes van dando paso a las pistas que sigue Brulé a lo largo de la novela buscando a la supuesta hija de Neruda y embarcándose a sí mismo en una serie de aventuras que delatan su vida amorosa. En palabras de Ampuero:

En El caso Neruda me interesaba el poeta que vuelve a Chile después de haber sido embajador de Allende en París. Es un Neruda que siente que le queda poco de vida por el cáncer que lo aqueja y porque también le queda poca vida al gobierno de su amigo Salvador Allende. Me interesaba ese Neruda solitario al final de su vida, el que, mirando el Pacífico, explora ensimismado su propia vida. Y como fue un hombre de muchas pasiones y mujeres, me interesaba que fuesen ellas, a través de su propio recuerdo, que lo describieran. Me interesaba que Neruda se viese críticamente a sí mismo a partir de las mujeres que fueron sus grandes amantes porque él tuvo relaciones muy controvertidas con ellas (2009).

Estas figuras femeninas resultan fundamentales ya que en la novela negra el papel de la mujer siempre es crucial: a veces rodeada de un halo de misterio, a veces sensual, distante, pero con una marcada presencia que ha de inspirar un caso, motivarlo o sencillamente formar parte de la vida del detective.

En esta obra, las mujeres pueden ser categorizadas por el lado de Neruda y por el lado de Brulé. Las mujeres de Neruda permiten organizar la estructura del texto y, al mismo tiempo, nos hacen observar cómo el personaje interactúa con la feminidad: a veces musas, a veces objetos sexuales; por momentos tangibles, en otros etéreas, pero siempre relegadas a un papel secundario en su vida, ya que el personaje de Neruda las usa y las desecha, las cambia continuamente en función de sus intereses y ésta parece ser la investigación que nos va dejando ver Brulé: la otra cara de un 
poeta que se dice amante de las mujeres pero para quien resultó imposible ser consistente en el afecto por una sola de ellas, ya que su amor parece estar enfocado sólo a sí mismo, a sus convicciones literarias y quizás a sus convicciones políticas, tal como observa el detective sobre su creador:

\begin{abstract}
Era demasiado. Le dolió el sorpresivo desprecio que sentía por aquel hombre que hasta ahora había ido admirando cada vez más. Mejor poner un límite a la caída, impedir que la porción amarga se comiera a la dulce, se devorara todo el pastel. [...] Cayetano sintió compasión y responsabilidad: por encima de cualquier juicio moral que las faltas de su primer cliente -y creador- le merecieran, de él dependía que alguna reparación fuera posible. Tenía una misión que cumplir (127-128).
\end{abstract}

En este pasaje, las emociones contradictorias del detective se agolpan, pero es evidente que se busca el distanciamiento, aprender a despegarse de su criterio individual, si bien sus ideas y su percepción del papel de las mujeres es diferente para Cayetano Brulé: él se distingue por una posición neutral que no revela ni a un gran amante ni a un gran misógino. En sus afectos y pasiones, el investigador parece ser un hombre más apacible, cuyo amor por su primera esposa lo transporta poco a poco a descubrir su vocación y a su locación geográfica: Chile es su patria por circunstancias de vida y por el hecho de que allí lo llevó ésta.

En este sentido, Ampuero plantea una característica que resulta interesante en su detective: una humanización que le quita la ficcionalidad típica del héroe de la novela negra, pues Cayetano Brulé no es el gran amante ni le interesa serlo. La mujer es parte importante y complementaria, como para todo ciudadano promedio, pero no es una búsqueda perpetua como fuente de creación ni mucho menos una obsesión. Las relaciones del detective, comparadas con las de Neruda, le conceden una dimensión neutral y humana donde a veces se gana y a veces se pierde; por momentos duele, en otros, simplemente sucede.

Resulta interesante observar estas características del detective en contraposición al personaje de Neruda que plantea la novela; la sencillez de Brulé, sin la búsqueda de la poesía, concede un mejor lugar a la figura femenina, ya que la lleva a un plano igualitario, más cercano al mundo cotidiano que al literario. En el caso del personaje de Neruda, la mujer va pasando por diversos estratos, por categorizaciones y transformaciones, mostrando la diferencia entre el detective y las obsesiones del artista. ¿ेPor qué entonces ir organizando la novela con base en los nombres de cada una de las mujeres de Neruda?

Tal vez porque en ello estriba la diferencia en la perspectiva con la que Ampuero va trazando el relato: el juego con la biografía del poeta organizado bajo el sistema de la feminidad que, además de inspiración, parece concederle su humanidad, sus contradicciones, ya que, para ser alguien que hablaba tanto del amor, en la novela el personaje parece no haber tenido nunca suficiente de ello, sea por ese marcado egoísmo, sea por el insinuado machismo o misoginia que manifiesta el personaje, tal como lo plantea el personaje de Laura, la tesista ocupada de la vida del poeta: "Escapó de Josie Bliss; abandonó a María Antonieta y a la hija; y arrojó como un estropajo a Delia. Y ahora que a Matilde le entraron los años y ya no es la mujer de antes, se está tirando a su sobrina. ¿Qué te parece el poeta? ¿̇Cómo se llaman esas cabronadas? ¿̇onetos, églogas, verso libre? Si no lo describes tú, ¿̇quién lo hará?" (241). 
Todos estos componentes permiten que la novela sea un caso de detectives que juega con el papel de la literatura en general: hacer de la vida una ficción que permite conceder dimensiones distintas a los personajes que la pueblan, ya que el verdadero caso Neruda no es la persecución de una misteriosa mujer cuya hija puede ser o no hija del poeta, sino que Brulé va poco a poco descubriendo al ser humano dentro del Nobel chileno, desvirtuado de literato, sólo visto de hombre a hombre.

De este modo, Ampuero parece ser más ecuánime con los personajes: a cada uno le va concediendo una dimensión humanizada, los coloca en un mismo plano, donde se observan y se crean mutuamente, donde la mitificación de una figura se anula y es posible adquirir una perspectiva más cercana al mundo cotidiano. La reelaboración de Neruda como personaje permite ver dentro del neopolicial latinoamericano una más de las dimensiones de esta literatura llena de posibilidades: no sólo el entretenimiento del lector con el crimen, sino un viaje literario que conecta al lector con diversos niveles: por un lado está la aventura detectivesca de Brulé y el juego con el personaje de Pablo Neruda. Por otra parte, está la relación histórica con el golpe de Estado durante la presidencia de Salvador Allende. Todo lo anterior bajo el hilo conductor de los nombres de las mujeres cuya presencia marcó a uno de los personajes principales de la novela.

Entonces, ¿̇por qué El caso Neruda se organiza bajo un índice de presencias femeninas? Si nos atenemos a que la novela es ficción y no un relato biográfico, podemos deducir que las figuras femeninas pasan de ser musas poéticas o incidentes vivenciales que ocurrieron al Nobel chileno a personajes concretos. Estas mujeres, bajo la crítica mirada de Roberto Ampuero, obtienen protagonismo, van más allá de la pista, ya que confieren dinamismo y motivación al relato literario, una de cuyas posibles lecturas parece ser que fueron las mujeres quienes concedieron esa misma vida al poeta.

Continuando con esa premisa, los nombres de estas mujeres organizan la novela como lo hicieron con la vida de Neruda: cada una dejando pistas y marcas, cuya profundidad correspondió a un periodo específico y a un aprendizaje que le supuso a éste un momento de su creación y de su existencia. El detective va siguiendo estos rastros como el lector: bajo una posible búsqueda donde hay un caso, pero éste es ya irresoluble: la vida de Neruda se escapa como lo hace su escurridizo pasado, desmenuzado en la novela.

La dimensión humana que concede la organización bajo los nombres femeninos permite a Ampuero conceder dentro de la novela una cierta "justicia literaria" a las mujeres que participaron en la vida del poeta. Como es posible cotejar con la biografía de Neruda, cada una de ellas tuvo una participación concreta (Josie Bliss, Maria Antonieta, Delia del Carril, Matilde Urrutia) que no sólo es parte de la ficción de este relato, sino que fue fragmento de una existencia real. En el libro, el personaje de Neruda confiesa que su prioridad era siempre la poesía y esto hace mella en el corazón de detective:

Lo confundía la revelación, lo entristecía el dolor del poeta y lo aterraba decepcionarlo. A la vez que encontraba mezquino y poco convincente ese argumento de que había sacrificado a su mujer y a la hija en nombre de una obra que hubiera compuesto de todos modos y que ya brotaba con ímpetu de su pluma cuando la niña nació. Pero con el paso de las 
semanas habían ido conquistándolo, tal vez el espíritu desconfiado del artista y su vulnerabilidad mal disimulada (126).

En la novela, Brulé no lo juzga, sólo acepta la humanidad del poeta. Y es posible observar la sugerente postura que hace Ampuero acerca de que no habría habido poesía sin las mujeres que participaron en la vida de Neruda. El escritor les concede una dimensión donde los personajes se encuentran en un mismo nivel, más allá de una biografía donde las figuras femeninas sólo parecen ser sombras inspiradoras en la vida de un gran hombre.

Ampuero muestra que no hay grandes hombres, sino grandes personajes en un mismo plano. Un bello modo de honrar, en la literatura, una representación de vida que no se dedica a enarbolar a un héroe, sino que concede una perspectiva más concreta y cercana al plano humano. En este juego, una y otra vez Ampuero destaca la presencia de la ficción como el hilo conductor de sus novelas, jugando con la perspectiva de los propios personajes, tal como el narrador permite ver en los pensamientos de Brulé:

\begin{abstract}
Ahora sabía por fin por qué los autores protegían tanto a sus protagonistas, especialmente si eran personajes de una serie. Interesados en cobrar anticipos por las siguientes novelas, los escritores se volvían dioses magnánimos y, torciéndole la mano a la realidad, les arrojaban salvavidas de último minuto a sus personajes [...] Mas él no era un personaje de ficción, aunque ahora quisiera serlo, sino el modesto investigador de un poeta herido de muerte, incapacitado para socorrerlo desde la distancia. Al menos él, Cayetano Brulé, era de carne y hueso, y no habitaba en una novela sino en la realidad, esa realidad implacable, donde no había dioses 0 , de haberlos, eran indiferentes e insensibles frente a los destinos humanos (207).
\end{abstract}

En este flujo de pensamiento la ilusión de ser real es parte de la ficción habitada por Brulé. Es el contacto que permite al lector creer en esta perspectiva mostrada por la novela, es una de las caras con las que la literatura de Ampuero se muestra ante su lector: con la intención de jugar a que el contrato de ficción es realista, tanto que hasta el detective puede creerlo sin cuestionarlo. Y es que, en este contexto, también se encuentra el papel de la historia, tal como plantea Benjamin R. Fraser: "Si bien es cierto que la ficción puede ser ficción y todavía interesarnos, conmovernos, y presentar una verdad que existe como real en un rincón ficticio del mundo real, entonces la historia puede ser tan ficticia como la ficción misma" (214).

\title{
3. El detective Brulé: creación para generar una nueva perspectiva literaria
}

La novela policiaca, como el resto de la literatura, plantea una cierta organización, un cierto modelo de la sociedad que la genera. En este sentido, Roberto Ampuero concibe el origen de Cayetano Brulé como el eje que demarca y explica sus características, que lo muestran como un detective que, como se ha visto hasta ahora, se determina por hallarse en medio de situaciones socio-históricas inesperadas: asumirlo con sencillez y con la capacidad de ir adaptándose a sus circunstancias, características que lo convierten en un cierto modelo de individuo latinoamericano que, sin ser el promedio, sí retrata mucho de cómo se va 
articulando la sociedad a través de diversas situaciones históricas, tal como plantea Colmeiro:

La novela policiaca negra supone una inversión del orden y signo de los principios éticos y estéticos. Aquí se mantiene la temática criminal como juego estético (suspense, misterio, ingenio) pero su importancia queda ahora desplazada o reducida con respecto al componente ético, que tiende a ocupar generalmente un lugar predominante. [...] De manera simultánea a la inversión de la relación entre los planos ético y estético, se altera la construcción de las fórmulas constitutivas. La "fórmula" del detective como superhombre con sobrenaturales poderes de observación y deducción da paso a la del detective como ser marginal curtido con una gran resistencia física y una cierta moral ambigua. [...] El detective no puede permanecer impasible ante la acción criminal y sus víctimas, a pesar de la máscara de "hombre duro" que está obligado a llevar a manera de defensa para subsistir en una sociedad que aplasta al más débil; su característico cinismo y su afilada ironía provienen del rechazo que siente hacia esa sociedad, de la que se siente marginado; el detective duro ha perdido su inmunidad y es tan vulnerable como cualquier otra víctima; su integridad física y moral está en constante peligro; se encuentra metido de lleno en la acción y la aventura de la investigación, la cual le llega a afectar personalmente (1994: 59).

Esta perspectiva crítica de la novela negra va enlistando cada uno de los puntos cuya relevancia enriquece a este género. ¿Cómo van articulándose tales situaciones en El caso Neruda? En primera instancia, no es que las situaciones éticas pierdan importancia, sino que el texto realiza una abstracción de estos valores; no es que confronte al lector con situaciones, sino que éstas han sucedido y, como todo pasado, son incuestionables: sólo es posible aceptarlas y articularlas, si es que tienen importancia para el resto de la historia.

En el presente caso, por supuesto que la tienen, ya que cada una de ellas presenta un momento crucial del pasado del personaje de Neruda, pero el narrador, más allá de criticarlo o de moralizar los sucesos, simplemente revela ese hecho con las razones del poeta. Ellas, dentro de su propio sistema de valores, resultan válidas, ya que son los argumentos con los que va nutriendo su existencia; en esa parte estriba uno de los encantos del detective: cuestionar esas afirmaciones cuando el pasado de Neruda le golpea de modo sorpresivo, pero mantiene su distancia y lo acepta, si bien su ética no tiene que coincidir con la de su creador.

El juego estético del mundo criminal en esta novela, particularmente, sólo muestra una parte de los sistemas con los que se rigen las Alemanias divididas de aquella época (1973) y el contexto del golpe de Estado en Chile, pero Brulé no tiene que resolver un crimen como tal, a diferencia de lo que ocurre en los otros libros que protagoniza. Si la novela debiera cumplir con ese requisito dentro del género negro, es posible entonces decir que se trata de un crimen metafórico, en el cual el poeta está tratando de resolver su pasado, asumiendo el crimen del abandono, el crimen de ser un cobarde que renunció a una mujer posiblemente embarazada de una hija suya en nombre de la literatura, en nombre de sus intereses particulares y su carencia de valor para encarar responsabilidades.

El último punto es el detective, su posición como "héroe" y sus habilidades para resolver el crimen. Cayetano Brulé, protagonista de cinco novelas de Roberto 
Ampuero, es un investigador que siempre se ve inmerso en casos que conllevan una situación política, que le explican mucho del mundo que habita pero, al mismo tiempo, son mucho más complicados, dado que la razón no es un elemento con el que América Latina pueda resolver este tipo de situaciones; puesto que la propia historia de este continente posee violencia, oscuridad y corrupción, tal como aparece en los casos de Brulé y que él mismo sabe que sucede, pero que, hábilmente, el narrador de la novela perfila como la realidad testimonial del detective: "Sin embargo, aquello que él afrontaba en esos instantes era la realidad cruel, implacable y caótica de América Latina, un mundo con una trama sin autor conocido ni guión preestablecido, donde todo era posible" (315).

En el caso de Cayetano Brulé, dentro del juego literario que reside, y por las características que posee este personaje, su mundo circundante tiene diferentes impactos, que muchas veces van desde la simpleza de lo práctico (situación con la que Ampuero le concede mayor realismo) u otras, como en El caso Neruda, donde ha de cambiar su visión del mundo, su formación como detective que parte de la literatura (desde el hecho de que se va creando una idea a partir de las lecturas que Neruda le sugiere) y, también, por qué Brulé se deja crear: es un personaje abierto al aprendizaje de lo que lee, observa y ávidamente incorpora a su experiencia.

Asimismo, el heroísmo o las acciones increíbles no son parte de la existencia de este personaje. Este detective se destaca por su determinación, su sentido práctico y su observación de la naturaleza del escenario que le rodea. Brulé no es un héroe dentro de los parámetros de la novela negra: no posee un físico impresionante, no es amante de los tiroteos, no es infalible y en muchos casos le toca ser golpeado salvajemente o llegar tarde para resolver el caso, como sucede en El caso Neruda:

\begin{abstract}
Cayetano rompió a llorar, a llorar desconsoladamente ante el cuerpo del poeta, sintió una opresión horrenda en el corazón, y se dijo que tal vez lo confundía con otra persona. Se limpió las lágrimas con la corbata de los guanaquitos estampados y escrutó de nuevo su rostro en la penumbra. Los grandes párpados cerrados, la frente amplia y lisa, las mejillas con los lunares y las patillas, el mohín de alivio asomado en la comisura de los labios, los zapatos de suelas gruesas... era él (319).
\end{abstract}

Ampuero, más que un héroe detectivesco, presenta en sus novelas a un hombre que va aprendiendo su labor sobre la marcha, que poco a poco se abre camino por su curiosidad, por su interés en preservar su trabajo y su capacidad para adaptarse. Es un personaje que evoluciona a lo largo de la saga que protagoniza. Pero también es un personaje que va contagiándose de ese sentimiento poético que le infunde Neruda, así como de la conciencia de habitar un continente profundamente mutable. Debido al contexto que lo origina, Brulé siempre se ha de distinguir por ser un conocedor de su mundo, de su tiempo y de cómo marcha la vida. Parece ser que Ampuero dota a este personaje de su capacidad de adaptación demostrando que ésta es su única arma para la vida detectivesca.

Cayetano Brulé es un personaje que sobrevive y supera sus circunstancias mediante la adaptación a un continente intrincado, a una historia discordante y a una serie de situaciones de las que no puede sentirse parte, dada su condición de forastero. Brulé es un detective que sabe que, como extranjero, es parte del mundo, pero elige tomar distancia para sobrevivir en la realidad que habita. 
Este personaje posee en esta característica, al mismo tiempo, una situación crítica y una propuesta de sobrevivencia: el distanciamiento que puede ser una forma de apatía para aquellos comprometidos con una causa o que se dicen militantes de muchas (en la novela este tipo de personajes se encuentran representados por ejemplo por Ángela, la esposa de Cayetano), pero es un modo de resistencia ante la historia ya que, como Cayetano va observando en las diferentes novelas, los sistemas totalitarios van tomando formas y máscaras distintas, asumen identidades y absorben todo tipo de adeptos. La historia, en el mundo de las novelas de Ampuero, es de una dureza cruda que permite comprender por qué el personaje elige no involucrarse con las causas, ya que esa historia es mutable y, justamente por su condición de extranjero, para Brulé es más cómodo adaptarse a las diferentes formas del disfrute de la cultura latinoamericana (belleza, paisajes, comida) que a alguna de sus radicales posturas políticas, tales como la dictadura cubana, la democracia o el socialismo. Para el detective, sólo los procesos históricos son modos de un momento, pero no se halla en posición de interesarse de modo profundo por alguno de ellos.

\section{Cayetano Brulé en la literatura}

El caso Neruda es una novela de origen y de continuidad para explicar la existencia del personaje del detective. Dentro de la saga que protagoniza, el texto demarca muchas explicaciones sobre su pasado, mostrando que en su vida no es el misterio lo que lo distingue, sino su capacidad de ser creado, de ser un producto literario por excelencia. El juego de la ficción con el que Roberto Ampuero sostiene a su detective es el diálogo permanente con la literatura. Más allá de buscar un realismo perenne o la crudeza de la historia, parece ser que el autor chileno le rinde tributo al discurso literario dentro del mismo.

A lo largo de su historia, la novela detectivesca posee distintos personajes, que van desde los analíticos personajes de Edgar Allan Poe (M. Dupin); Sherlock Holmes, de Conan Doyle; Philip Marlowe, de Raymond Chandler, o los habitantes del pulp, entre ellos, el poco ortodoxo Nick Belane de Charles Bukowski, quienes van permitiendo que el género evolucione, cambie con la época y con los lectores. Entonces, dentro de la novela policiaca latinoamericana, ¿qué es lo que está proponiendo Roberto Ampuero a través de Cayetano Brulé?

Este personaje, como se ha analizado hasta el momento, escapa a la primera tradición del género policial, ya que no tiene un carácter heroico y su moral responde ajustándose al lugar, al caso y a las situaciones en las que se encuentre (si bien jamás revela una postura estricta sobre su ética o reglas bajo las cuales se rija). Brulé es un latinoamericano muy bien adaptado que emplea sus conocimientos, su acento, sus intuiciones y su carácter según convenga a su sobrevivencia. Otro de los componentes que distinguen a Brulé es generado a través del narrador, quien juega con la crudeza de la realidad circundante, con el contexto histórico a la par que construye este universo bajo la premisa lúdica de la ficción literaria; de la literatura jugando dentro de la literatura misma a que ésta es real.

Este recurso estilístico, que en los últimos años aparece con un halo de misterio en escritores contemporáneos como Enrique Vila-Matas (España) o Paul Auster (Estados Unidos), entre otros, que sin ser específicamente escritores del género policiaco 
emplean la ficción literaria en diálogo con la literatura misma como una forma de renovar, de intertextualizar y, por supuesto, con este recurso, generan un diálogo dentro del propio sistema literario, sea a modo de homenaje, parodia o como mera referencia intertextual.

La aportación que Roberto Ampuero elabora con el personaje de Brulé, a partir de El caso Neruda, es mantener vivo el interés por la literatura como sistema, independientemente del género del que se trate, pues muestra que dentro del género policiaco puede hallarse un sistema que no es ajeno a la literatura en general ni mucho menos al contexto latinoamericano contemporáneo (tanto literario como histórico), ya que cumple con el cometido de ésta: ofrecer una historia que muestra facetas de los seres humanos, a la vez que juega dentro del propio sistema literario con las reglas de la ficción y permite un acercamiento a la realidad histórica a través de los encuentros del investigador con el poder, tal como destaca Benjamin F. Fraser:

\begin{abstract}
Este énfasis en el poder no sólo hace hincapié en la estructuración del texto mismo pero simultánea y consecuentemente en la estructura de la sociedad en que se encuentran el autor, el narrador, el detective y el lector. A través de un corpus de estrategias narratológicas variadas, la novela detectivesca latinoamericana cumple con su misión de ser una literatura políticamente comprometida y logra restaurar los problemas de justicia literarios al mundo nuestro de la violencia política, sistemática y real (2006: 199-200).
\end{abstract}

El compromiso literario que muestra la novela es circular, ya que cada uno de los planos sostiene una premisa que cuestiona o relaciona el plano humano con el histórico y que, al mismo tiempo, fascina a los lectores con una de las aventuras del detective. En este sentido, Ampuero logra que la novela policiaca "le ensucie las manos" al lector, ya que lo sumerge en la historia y le obliga a mirar con distintos ojos las posibilidades de ésta, destacando las distintas perspectivas y los diferentes momentos, la diversidad de sus personajes y la crudeza de todos esos encuentros en un mismo plano.

\title{
Bibliografía
}

AMPUERO, R. (2008): El caso Neruda. Bogotá. Editorial Norma.

- (2008) "Entrevista a Roberto Ampuero". Capital Online, 3/09/2008. Disponible en: http://www.capital.cl/poder/2008/09/03/140920-entrevista-a-roberto-ampuero

COLMEIRO, J. (1994): La novela policiaca española: teoría e historia crítica. Barcelona: Anthropos.

FRANKEN K. y A. CLEMENS (2002): "La asimilación de la novela policial cubana en Roberto Ampuero." Anales de literatura chilena. 3, pp. 89-105.

FRASER, B. (2006): "Narradores contra la ficción: La novela detectivesca como estrategia política." Studies in Latin American Popular Culture, 25, pp. 199-219.

GADAMER, H. G. (1997): Mito y Razón. J. F. ZÚÑIGA GARCÍA (Trad.). Barcelona: Paidós Studio.

GARCÍA-CORALES, G. (1999): "Nostalgía y melancolía en la novela detectivesca del Chile de los noventa." Revista Iberoamericana. Vol. LXV, 186, pp.81-87. 
MARÚN, G. (2006): La narrativa de Roberto Ampuero en la globalización cultural. Santiago de Chile: Mare Nostrum.

MUÑÓZ, J.A. (2009): "Entrevista a Roberto Ampuero, autor de El caso Neruda". Revista Letras. 29/07/2009. Disponible en : http://revistadeletras.net/entrevista-a-roberto-ampuero-autor-de-el-casoneruda/

PROMIS, José. (2005): "El neopolicial criollo de Ramón Díaz Ełerovic". Anales de literatura chilena. 6, pp. 151-167.

TOLEDO, V. B. (2003): "Nueva novela policiaca: un nuevo modelo exegético." Mester. 32/1, pp.155-178. 